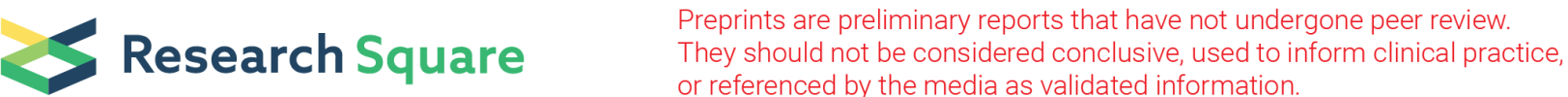

\section{The Time to Initiate Trophic Feeding and Its Predictors Among Preterm Neonate Admitted to Neonatal Intensive Care Unit, Multicenter Study, Northwest Ethiopia, 2020.}

\section{Daniel Adimasu}

DebreMarkos Comprehensive Specialized Hospital

\section{Yilikal Tafere}

Debre Markos University College of Health Science

\section{Teodros Eshetie}

Debre Markos University College of Health Science

\section{Bekalu Endalew}

Debre Markos University College of Health Science

Ermias Abebaw ( $\square$ fjeremy23@gmail.com )

Debre Markos University

\section{Mekonen Adimasu}

Addis Ababa University College of Health Sciences

\section{Research}

Keywords: Trophic, preterm, neonates, Ethiopia

Posted Date: August 12th, 2021

DOl: https://doi.org/10.21203/rs.3.rs-786698/v1

License: (c) (i) This work is licensed under a Creative Commons Attribution 4.0 International License.

Read Full License 


\section{Abstract}

Background: Trophic feeding is a small volume, hypo-caloric feeding, gut priming or minimal enteral feeding acclimate the immature gut of enteral fasting preterm neonates. Delayed starting of trophic feeding had resulted in short and long-term physical and neurological sequels. The current study aimed to assess time to initiate trophic feeding and its predictors among preterm neonates admitted in the neonatal intensive care unit of Debre Markos, Felege Hiwot, and Tibebe Ghion comprehensive specialized hospitals.

Methods: An institutional-based prospective follow-up study was conducted among 210 neonates. The data were collected with interview and chart review, entered into Epi data 3.1 and exported to Stata 14.1 for analysis. Multivariable Cox regression models were fitted to identify predictors of time to initiate trophic feeding.

Result: A total of 210 neonates were followed for 10136 person-hours of risk time and 191 (90.95\%) of neonates were started trophic feeding. The overall incidence of starting trophic feeding was 2 per 100 (95\% Cl: 2, 2.2) person-hours observations. The median survival time was 42 hours ( $95 \% \mathrm{Cl}: 36,48)$. APGAR- score at first minute $<7$ (AHR: $0.6,95 \%$ Cl: 0.44, 0.82), gestational age of $<34$ weeks (AHR: 0.69 , $95 \% \mathrm{Cl}: 0.5,0.94)$, presence of respiratory distress syndrome (AHR: $0.5,95 \% \mathrm{Cl}: 0.36,0.68$ ), presence of hemodynamic instability (AHR: $0.37,95 \% \mathrm{Cl}: 0.24,0.57$ ), presence of perinatal asphyxia (AHR: $0.63,95 \%$ Cl: $0.44,0.89$ ), cesarean section delivery (AHR: $0.63,95 \% \mathrm{Cl}: 0.44,89)$ and being delivered within the study hospitals (AHR: $0.54,95 \% \mathrm{Cl}: 0.39,0.74$ ) were found to be statistically significant predictors of time to initiate trophic feeding.

Conclusion: There was a significant delay to initiate trophic feeding in the studied hospitals. Gestational age of below 34 weeks, APGAR-score of less than seven, out-born delivery, cesarean delivery, presence of respiratory distress syndrome; perinatal asphyxia, and hemodynamic instability were predictors of delay in starting of trophic feeding. Standardized feeding guideline has to be implemented to overcome delays in enteral feeding initiation.

\section{Background}

Preterm birth is defined as a birth before 37 completed weeks of gestation or fewer than 259 days from the first date of a woman's last menstrual period. The global estimate of preterm birth was $11.1 \%$ and $10.6 \%$ in 2010 and 2014, respectively. This has a great regional variation which was ranged approximately $5 \%$ in some European countries; and $18 \%$ in Sub-Saharan countries. This showed that low and middle-income countries account for the majority of the world's preterm births, $60 \%$ of it occurred in Sub-Saharan and South Asia countries $(1,2)$.

Provision of intense nutritional support with both parenteral and enteral nutrition to preterm neonates born prematurely is necessary. This helps to attain the rate and composition of weight gain approximating the normal neonate at the postmenstrual age, to minimize postnatal growth failure and 
the risk of enterocolitis; and to optimize neurodevelopmental and long term health outcomes. To tackle this problem trophic feeding (TF) is the preferred choice of preterm feeding. (3)

Trophic feeding is usually defined as serving small volumes of enteral feeding (EF) which is started within the first few postnatal days. It is minimal enteral nutrition (MEN), gut priming, or hypo-caloric feeding that acclimate the immature gut of enteral fasting in preterm neonates. It is feeding nutritionally insignificant amounts $(1-2 \mathrm{~mL} / \mathrm{kg} / \mathrm{dose}$ or $10-15 \mathrm{ml} / \mathrm{kg} /$ day) for immature neonates but stimulates and supplies nutrients to the developing gastrointestinal system (4). Its aim is not to feed the baby but the intestine, preferably with colostrum (5). It is the nutrition provided shortly after birth in an attempt to avoid or reduce parenteral nutrition and its related complications (6-9).

Those starting TF have more energy intake, improved feeding tolerance, greater and faster weight gain and head growth, less sepsis, significantly fewer days of parenteral nutrition and oxygen supplementation, and consequently earlier discharge $(3,14-18)$.

TF reduces the incidence of complications related to enteral fasting and parenteral nutrition like hyperbilirubinemia, gut atrophy, decrease gastrointestinal mass, infections, and cholestasis $(3,10,11,13$, 19-21), and metabolic complications (20) without an increase in the risk of NEC (4). Early initiation of EF with the mother's own milk and prevention of postnatal growth failure is the target of nutrition in preterm neonates $(5,7)$.

Researches demonstrated that there is a considerable delay in the initiation of enteral feeding in preterm neonates worldwide. For instance, researchers reported that 80 to $90 \%$ of neonates did not start TF until 48 hours of age. And in another study, $40 \%$ of neonates were in enteral fasting until 96 hours of age (23, 24). According to one study $76 \%$ of preterm neonates had been kept nothing per os (NPO) during the first 24 hours and $22 \%$ were kept for 72 hours. These neonates who started enteral feeding was getting only $10 \%$ dextrose intravenously. Overall, the neonates were kept NPO in $26.8 \%$ of the time while they were in NICU (25).

Despite the general recommendation to initiate early enteral feeding, a considerable number of the preterm neonates are kept NPO in the first few days and receiving only maintenance fluid. The inherent problems of immature gut motility and function as well as the fear of necrotizing enterocolitis and feeding intolerance are the two major reasons that delay the start of preterm feeding (3). This is associated with an increased risk of neonatal mortality (25). There is a marked dose response of increasing risk of neonatal mortality with increasing delay in initiation of breastfeeding. The overall late initiation was associated with a 2.4 -fold increase in the risk of neonatal mortality (26) and other neonatal bad outcomes $(25,27)$ and highly associated with postnatal growth failure $(28)$.

The initiation, mode, and rate of advancement of TF remained a topic of controversy $(10,29)$. Practices across NICUs and professionals are different. This variability includes preterm feeding practice which is not in line with the national guidelines (25). 
Different findings indicate that there is a significant delay in starting TF across the globe and evidence on time to TF among preterm neonates admitted to NICU in Ethiopia is not adequately searched. Therefore, this study was aimed to estimate the time to initiate TF among preterm neonates admitted to NICU in three comprehensive specialized hospitals found in Debre Markos and Bahir Dar, Northwest Ethiopia.

\section{Methods}

\section{The Study Design, period and population}

An institutional-based prospective follow up study was conducted. The study was conducted in neonatal intensive care units of Debre Markos, Felege Hiwot, and Tibebe Ghion comprehensive specialized hospitals, that the former found in Debre Markos town and the latter two found in Bahir Dar town, Amhara.

Debre Markos is located $300 \mathrm{~km}$ from Addis Ababa, the capital city of Ethiopia, and $256 \mathrm{~km}$ from BahirDar, which is $556 \mathrm{~km}$ away from Addis Ababa. Debre Markos (DMCSH), Felege Hiwot (FHCSH), and Tibebe Ghion (TGCSH) Comprehensive Specialized Hospitals have 162, 230, and 151 monthly and 1845, 2479 , and 1652 annual neonatal admission according to the 2012 EFY report, respectively. Of these 63 , 89 , and 67 ; and 612,834 , and 660 were monthly and annual admissions of preterm neonates, respectively. These hospitals are equipped with 28,43 , and 27 neonatal beds and 24,35 , and 18 maternal beds respectively.

All of these hospitals are the final referral choice for other health institutions around and provide tertiary level neonatal care and are organized with necessary materials, equipment and health professional mixes.

These are organized into different service areas including term, preterm, isolation, and procedure rooms with $\mathrm{KMC}$ and maternal waiting rooms. The major services are general neonatal care, blood and exchange transfusion, phototherapy, and ventilation support such as CPAP. This study was conducted in these hospitals from October 1 to November 30/2020. Study participants were recruited and followed for the first seven postnatal days.

The study population included all preterm neonates admitted to the neonatal intensive care unit of Debre Markos, Felege Hiwot, and Tibebe Ghion comprehensive specialized hospitals during the study period. Inclusion Criteria

Neonates born after 28 completed weeks, but before 37 completed weeks, and admitted to the neonatal intensive care unit of these hospitals.

\section{Exclusion Criteria}

Neonates who had started direct breast milk or other option of feeding before the time of admission, prediagnosed stage II/III necrotizing enterocolitis, stage III perinatal asphyxia, unknown gestational age, 
unknown APGAR score, and birth weight were excluded from this study.

\section{Sample Size and sampling technique}

The sample size was computed by using STATA (version 14) considering this statistical assumptions; two-sided significant level (a) of $5 \%$, power $80 \%, Z_{a / 2}=Z$ value at $95 \%$ confidence interval $=1.96$, death rate $=50 \%$, Hazard Ratio $(H R)=0.5$, Survival probability $=0.5$, the proportion of withdrawal $=0.15(45)$.

The study population was preterm neonates on whom trophic feeding is more commonly practiced. Neonates that doesn't fulfill eligibility criteria were recruited from respective study hospitals. From neonates who were twin or triplet, only one of them was included by lottery method at each spot. A total sample of 210 children were finally selected randomly.

\section{Data Collection Procedure}

Data was collected using a semi-structured pretested English version questionnaire and extraction checklist through face to face interview and chart review. The content of the questionnaire includes neonatal and maternal socio-demographic variables, neonatal and maternal related factors, and health service-related factors. The data extraction checklist and questionnaire were adapted from different related literature, books, and guidelines $(13,22,28,35,36,37,42-44,47,48)$.

Besides the principal investigator, six nurses working at NICU, two from each respective hospital, as a data collector, and three nurses as a supervisor were participated throughout the data collection process.

Baseline data were obtained soon after admission, and the rest of the data were obtained every day in the follow-up period. Supervisors had been following the data collection process every day.

\section{Data Processing and Analysis}

The data were checked for completeness, coded, and entered into Epi-data version 3.1; and exported to Stata/SE 14.0 for data cleaning and analysis.

Continuous data were reported with a mean (standard deviation) and median (interquartile range). The data with categorical nature was described with frequency and proportion. The outcomes of study participants were dichotomized into (code ' 1 ') as a failure and (code ' 0 ') as a censor. Some continuous variables were categorized for ease of analysis and otherwise used as continuous. The variance inflation factor (VIF) and correlation matrix were used to assess multi-collinearity.

The Kaplan Meier survival curve was used to estimate survival time, and a log-rank test was used to compare the survival curves of categorical variables. The necessary assumption of the Cox-proportional hazard regression model was checked using the Schoenfeld residual test, the graphical methods, and the presence of a time-dependent covariate. The overall model adequacy and fineness were assessed using the Cox-Snell residuals and global fit test, respectively. Then, bi-variable Cox-regression was computed for 
each predictor variable, and a P-value of $<0.25$ was used as a cut-off point to enter variables to multivariable Cox-regression. The variables were selected through backward stepwise procedures. The confounding effect was minimized using proper inclusion and exclusion criteria and a multi-variable analysis.

The result of the final model was expressed in terms of adjusted hazard ratio (AHR) with $95 \%$ confidence intervals. The significant association was declared with a p-value less than 0.05 in a multivariable Cox regression model. Finally, the result of this study is presented with tables, graphs, or text narrations.

\section{Operational Definitions and Definition of Terms}

Early feeding: neonates start trophic feeding within 24 hours of birth $(28,30)$.

Delayed feeding: neonates start trophic feeding after 24 hours of birth(30).

Survival time: the length of time in hours followed starting from birth to the first trophic feeding

Event: the neonates who had started first trophic feeding within the follow-up period.

Censored: neonates who died left against medical advice, transferred or referred before starting trophic feeding, or not started at end follow-up.

Follow up time: time from birth to the first seven days of life.

Hemodynamic instabilities: Blood group and RH incompatibility, anemia, polycythemia, bleeding disorders, blood glucose disturbances (46).

Trophic feeding: The first minimal enteral feeding to prime the gut regardless of method or volume (30).

\section{Results}

\section{Neonatal and maternal socio-demographic characteristics}

In this prospective follow-up study, a total of 278 preterm were admitted to these units from October 1 to November 30, 2020. Of these 48 were excluded. This left with a total of 210 preterm neonates with the mean gestational age of 33 ( \pm 3 standard deviation) completed weeks and a minimum of 28 to a maximum of 36 weeks. About 191 (90.95\%) neonates were started TF and 19 (9.1\%) were censored due to death.

Among neonates included in the study, all of them were low birth weight with a mean weight of 1549.9 ( \pm 353.5 standard deviation) grams with a minimum of 850 grams to a maximum of 2400 grams. Concerning weight for gestational age, about 157 (74.8\%) was appropriate for their gestational age. The mean age of mothers was 27.4 ( \pm 5.05 standard deviation) years with a minimum of 18 years and a 
maximum of 40 years. Among mothers interviewed, greater than half $(60.9 \%)$ were residing in a rural area. (Table 1)

Table 1

Socio-demographic characteristics of the mothers and neonates admitted in NICU of DMCSH, FHCSH, and TGCSH comprehensive specialized hospitals, Amhara, Northwest Ethiopia, $2020(\mathrm{~N}=210)$

\begin{tabular}{|c|c|c|c|}
\hline Variables & Categories & Frequency & Percentage \\
\hline \multirow[t]{4}{*}{ Maternal education } & Not attend formal education & 79 & 37.6 \\
\hline & Primary & 47 & 22.4 \\
\hline & Secondary & 47 & 22.4 \\
\hline & Secondary \&above & 37 & 17.6 \\
\hline \multirow[t]{2}{*}{ Gestational age in week } & $<34$ weeks & 124 & 59.05 \\
\hline & $\geq 34$ weeks & 86 & 40.95 \\
\hline \multirow[t]{2}{*}{ Birth weight in gram } & $850-1499$ & 86 & 40.95 \\
\hline & $1500-2499$ & 124 & 59.05 \\
\hline \multirow[t]{5}{*}{ Maternal age } & $\leq 19$ & 11 & 5.2 \\
\hline & $20-24$ & 56 & 26.7 \\
\hline & $25-29$ & 65 & 31 \\
\hline & $30-34$ & 58 & 27.6 \\
\hline & $\geq 35$ & 20 & 9.5 \\
\hline
\end{tabular}

\section{Neonatal related factors}

The mean APGAR-score of neonates at the first and fifth minute was 6 ( \pm 1.96 standard deviation) and 7.4 ( \pm 1.29 standard deviation), respectively. In this study, most (86.38\%) of neonates were passed their first meconium before starting TF.

\section{Maternal related factors}

Among neonates included in the study, 54.76\% were referred. More than half 142 (67.62\%) of them were born with spontaneous vaginal delivery. Almost half (54.76\%) of mothers were primiparous and 110 $(52.38 \%)$ of their current birth was a singleton. 


\section{Survival status of neonates on time to initiate TF}

A total of 210 neonates to mother pairs were followed for 10136 person-hours of risk time. The minimum and maximum time of follow-up was 5 and 141 hours respectively. The cumulative probabilities of starting TF by the end of 24,48 , and 72 hours were $22 \%, 53.8 \%$, and $72.74 \%$, respectively. The overall incidence of starting TF was 2 per 100 (95\% Cl: 1.6, 2.2) person-hours. The incidence rate that preterm neonates start TF was $5.67,2.51,1.53$, and 0.94 per 100 person-hours in the first $24,48,72$, and greater than 72 hours after birth, respectively. The median follow-up time was 38 (IQR: 25-70) hours. The median survival time was 42 (IQR: $26-72)(95 \% \mathrm{Cl}: 36,48)$ hours. (Table 2$)$

Table 2

survival probabilities to start TF among neonates admitted in NICU of DMCSH, FHCSH, and TGCSH comprehensive specialized hospitals, Amhara, Northwest Ethiopia, 2020

\begin{tabular}{|c|c|c|c|c|c|}
\hline $\begin{array}{l}\text { Time } \\
\text { interval }\end{array}$ & $\begin{array}{l}\text { Beginning } \\
\text { total }\end{array}$ & $\begin{array}{l}\text { Start } \\
\text { feeding }\end{array}$ & Censored & $\begin{array}{l}\text { Cumulative survival } \\
\text { probability }\end{array}$ & $95 \% \mathrm{Cl}$ \\
\hline 024 & 210 & 41 & 6 & 0.8019 & $\begin{array}{l}(0.74 \\
0.85)\end{array}$ \\
\hline 2448 & 163 & 71 & 10 & 0.4416 & $\begin{array}{l}(0.37 \\
0.52)\end{array}$ \\
\hline 4872 & 82 & 31 & 2 & 0.2726 & $\begin{array}{l}(0.21 \\
0.34)^{\prime}\end{array}$ \\
\hline 7296 & 49 & 25 & 0 & 0.1335 & $\begin{array}{l}(0.09 \\
0.19)\end{array}$ \\
\hline 96120 & 24 & 13 & 1 & 0.0597 & $\begin{array}{l}(0.03, \\
0.11)\end{array}$ \\
\hline 120144 & 10 & 10 & 0 & 0.0000 & . . \\
\hline
\end{tabular}

In addition to the overall survival estimate, the survival experience of neonates with different categorical variables was executed to compare the status of TF between or across groups. The statistical significance of the difference in the survival experience of TF was checked with a log-rank test $(p<0.05)$. Even though this process is executed for all categorical variables, some of them are displayed for ease of presentation. Further analysis comparing the median time to initiate TF based on respiratory distress syndrome showed that there was a significant difference in median starting time, 53 and 27 hours among those with and with no respiratory distress syndrome. Likewise, there was a significant difference in median time to initiate TF between different groups of neonates. ( Table 3) 
Table 3

The group-specific median time of starting TF among neonates admitted in NICU of DMCSH, FHCSH, and TGCSH, Amhara, Northwest Ethiopia from October to November / $2020(n=210)$

\begin{tabular}{|c|c|c|c|}
\hline Predictors & Category & $\begin{array}{l}\text { Median survival time }(95 \% \\
\mathrm{Cl})\end{array}$ & $\begin{array}{l}\text { Log-rank test } p \text { - } \\
\text { Value }\end{array}$ \\
\hline \multirow{2}{*}{$\begin{array}{l}\text { Respiratory distress } \\
\text { syndrome }\end{array}$} & No & $27(21.42,32.58)$ & \multirow[t]{2}{*}{$<0.0001$} \\
\hline & yes & $53(44.80,61.20)$ & \\
\hline \multirow[t]{2}{*}{ Perinatal asphyxia } & No & $37(31.24,42.76)$ & \multirow[t]{2}{*}{0.002} \\
\hline & Yes & $65(45.32,84.68)$ & \\
\hline \multirow[t]{2}{*}{ Hemodynamic instability } & No & $37(31.36,42.65)$ & \multirow[t]{2}{*}{$<0.0001$} \\
\hline & Yes & $96(83.62,108.38)$ & \\
\hline \multirow[t]{2}{*}{ Gestational age } & $<34$ weeks & $48(42.07,53.93)$ & \multirow[t]{2}{*}{$<0.0001$} \\
\hline & $\geq 34$ weeks & $30(24.71,35.29)$ & \\
\hline \multirow[t]{2}{*}{ 1st minute APGAR score } & $\geq 7$ score & $32(25.32,38.68)$ & \multirow[t]{2}{*}{$<0.0001$} \\
\hline & $<7$ score & $55(42.19,67.81)$ & \\
\hline \multirow[t]{2}{*}{ Place of delivery } & in-born & $32(27.50,36.50)$ & \multirow[t]{2}{*}{$<0.0001$} \\
\hline & out-born & $53(38.19,67.81)$ & \\
\hline \multirow[t]{2}{*}{ Mode of delivery } & SVD & $36(30.21,41.79)$ & \multirow[t]{2}{*}{0.002} \\
\hline & $\begin{array}{l}\text { Cesarean } \\
\text { section }\end{array}$ & $60(40.16,79.85)$ & \\
\hline
\end{tabular}

From graphs below, the first graph shows the overall survival curves to initiate TF among followed neonates (Fig. 1), and the second graph indicates the difference in survival probability to initiate TF between groups of neonates with a birth weight of < 1500 grams wait longer to start TF compared to those with $\geq 1500$ grams ( Fig. 2)

\section{Cox-proportional hazard assumption}

The assumptions of Cox proportional hazard of all predictor variables were checked with graphical testing parallelism of survival curves by log-log plot curves (covariate versus $\ln ($ analysis time)) and proximity of curves by Kaplan-Meier observed survival curves and the Cox predicted curves, among different groups of categorical predictors. The Schoenfeld residual test and time-varying covariate were used to test Cox proportional hazard assumptions statistically. 


\section{Predictors of time to initiate TF}

After bi-variable cox regression, diabetes mellitus, gestation, educational status, residence, age of the mother, meconium aspiration syndrome, meconium passage, sucking reflex, obstructions, blood transfusion, sero-status of the mother, and birth defect were not entered into multi-variable analysis because of $p$-value $>0.25$. Then, Multivariable analysis was executed for gestational age, birth weight, Weight for gestational age, first minutes APGAR-score, fifth minutes APGAR-score, continuous positive air pressure, phototherapy, perinatal asphyxia, hemodynamic instabilities, respiratory distress syndrome, frequency of order revision, maternal hypertensive disorder of pregnancy, parity, mode and place of delivery. Finally, seven variables were identified as statistically significant independent predictors $(95 \% \mathrm{Cl})$ for time to initiate TF (Table 4). 
Table 4

the final model containing predictors of time to initiate TF among neonates who were admitted to NICU of

DMCSH, FHCSH and TGCSH, Amhara, Northwest Ethiopia from October to November /2020 $(\mathrm{n}=210)$

\begin{tabular}{|c|c|c|c|c|c|}
\hline \multirow[t]{2}{*}{ Predictor variables } & \multirow[t]{2}{*}{ Categories } & \multicolumn{2}{|c|}{$\begin{array}{l}\text { Starting } \\
\text { TF }\end{array}$} & \multirow[t]{2}{*}{ CHR $(95 \% \mathrm{Cl})$} & \multirow[t]{2}{*}{$\operatorname{AHR}(95 \% \mathrm{Cl})$} \\
\hline & & Yes & No & & \\
\hline \multirow[t]{2}{*}{ First minute APGAR score } & $<7$ score & 99 & 11 & $0.48(0.35,0.64)$ & $0.6(0.44,0.82)^{*}$ \\
\hline & $\geq 7$ score & 92 & 8 & 1 & 1 \\
\hline \multirow[t]{2}{*}{ Gestational age } & $<34$ weeks & 113 & 11 & $0.59(0.44,0.78)$ & $0.69(0.5,0.94)^{*}$ \\
\hline & $\geq 34$ weeks & 78 & 8 & 1 & 1 \\
\hline \multirow[t]{2}{*}{ Respiratory distress syndrome } & Yes & 112 & 10 & $0.47(0.35,0.63)$ & $0.5(0.36,0.68)^{\star \star}$ \\
\hline & No & 79 & 9 & 1 & 1 \\
\hline \multirow[t]{2}{*}{ Perinatal asphyxia } & Yes & 45 & 5 & $0.59(0.42,0.82)$ & $0.63(0.44,0.89)^{*}$ \\
\hline & No & 146 & 14 & 1 & 1 \\
\hline \multirow[t]{2}{*}{ Weight for gestational age } & SGA & 47 & 6 & $0.7(0.54,0.97)$ & $0.74(0.52,1.04)$ \\
\hline & AGA & 144 & 13 & 1 & \\
\hline \multirow[t]{2}{*}{ Hemodynamic instability } & Yes & 39 & 1 & $0.26(0.17,0.38)$ & $0.37(0.24,0.57)^{\star \star}$ \\
\hline & No & 152 & 18 & 1 & 1 \\
\hline \multirow[t]{2}{*}{ Place of birth } & Out-born & 107 & 8 & $0.47(0.36,0.65)$ & $0.54(0.39,0.74)^{\star \star}$ \\
\hline & In-born & 84 & 11 & 1 & 1 \\
\hline \multirow[t]{2}{*}{ Mode of delivery } & CS & 63 & 5 & $0.62(0.46,0.84)$ & $0.63(0.44,89)^{\star}$ \\
\hline & SVD & 128 & 14 & 1 & 1 \\
\hline
\end{tabular}

According to this table (Table 4), seven variables were found to be significantly predicting factors of time to initiate TF. Among these, the first minute APGAR-score was a statistically significant variable. The hazard of Starting TF among neonates scored below seven APGAR at the first minute were $40 \%$ less likely as compared to neonates with seven and above score (AHR: $0.6,95 \% \mathrm{Cl}: 0.44,0.82$ ). The hazard of starting TF among neonates born with less than 34 weeks of gestation was $31 \%$ less likely compared to those born with 34 and above weeks of gestation (AHR: 0.69, 95\% Cl: 0.5, 0.94) (Fig. 4). Another predictor was the presence of respiratory distress syndrome that the hazard of starting TF was $52 \%$ less likely 
among neonates who have suffered from this problem compared with their counterparts (AHR: $0.5,95 \%$ Cl: 0.36, 0.68) (Fig. 3).

The presence of hemodynamic instability was found to be a statistically significant predictor of time to initiate TF (Table 4). With this regard, the hazard of starting TF among neonates who have hemodynamic instability was $67 \%$ less likely compared to neonates with no these problems (AHR: $0.37,95 \%$ Cl: 0.24, 0.56). The hazard among neonates diagnosed with perinatal asphyxia was $36 \%$ less likely to start TF compared with their counterparts (AHR: $0.63,95 \% \mathrm{Cl}: 0.44,0.89$ ).

In addition to these predictors, the hazard of giving delivery with cesarean section was $31 \%$ less likely to start TF than that of spontaneous vaginal delivery (AHR: 0.63, 95\% Cl: 0.44, 89) (Table 4). Place of delivery was also found to be statistically significant predictors of time to initiate TF. Neonates, who were not born within the study hospitals, were $47 \%$ less likely to start TF than those born within the study hospitals (AHR: 0.54, 95\% Cl: 0.39, 0.74).

The overall adequacy of the final fitted model was checked by the Cox-Snell residuals were estimated based on the Kaplan-Meier estimated survivor function. This graphical plot of the cumulative hazard versus cox-Snell residuals showed an approximate straight line with slope one and indicates the model fits the data. And in addition to the Cox-Snell residuals graph, the final model was tested statistically for its fitness by using the global goodness of fit test which was decided as adequate if its $p$-value is greater than 0.05 . Based on this, the global goodness of fit test for this final model was $p$-value $=0.59$ (Fig. 4 ).

\section{Discussion}

This study aimed to assess the time to initiate TF and its predictors among preterm neonates admitted in the study hospital within the study period. In this study, the incidence of starting TF was 2 per 100 personhours of risk time. At the end of follow-up, $90.9 \%$ of neonates ( $95 \% \mathrm{Cl}: 86.2 \%, 94.2 \%)$ were started TF. Among those who started TF, only $52(24.76 \%)$ of preterm neonates started within the first 24 hours of birth. In this study, $63.33 \%$ and $79.05 \%$ of preterm neonates started TF within the first 48 and 72 hours of birth, respectively. This indicates that only a small proportion of preterm neonates started TF within the first 24 hours of birth. This finding is lower as compared to an observational study in Tuscany (74.1\%), a cohort study in Iran $(36 \%)$, and New Zealand $(60 \%)(23,31)$. This finding on the proportion of neonates who started TF within 48 hours is consistent with the finding (63.2\%) in a cohort study on preterm neonates in NICU of the Islamic Republic of Iran (23), but higher than the finding Nigerian Special Care Baby Unit (40\%) (33); and lower than a study finding in Uganda rural hospitals (80\%) (28) and New Zealand (80\%) (22).

In this prospective follow-up study, the median time to start TF was 42 (IQR: 26-72) hours which is higher than the finding reported as 24 hours in a retrospective study in New Zealand (32). The difference might be due to the study setup, study design (prospective versus retrospective), sample size (210 versus 647), and socio-demographic variations, and differences in regional variation in neonatal management protocols (Ethiopia versus New Zealand). 
According to this study, gestational age of below 34 weeks, APGAR-score of less than seven, out-born delivery, cesarean delivery,presence of respiratory distress syndrome, perinatal asphyxia, and hemodynamic instability were predictors of delay in starting of trophic feeding.

Among these predictors, gestational age was one predictor of time to initiate TF. The hazard of starting TF among neonates born less than 34 weeks of gestation was $29 \%$ less likely compared to those born 34 and above weeks of gestation. This might be due to differences in physiological maturity among these groups of neonates on whom necrotizing enterocolitis and feeding intolerance are common in the former group of neonates. This finding is supported by a web-based survey on tertiary NICUs in different countries that revealed that the lower gestational age was the reason for the delayed starting of TF (12). Another survey research done in the United States and Canada also identified lower gestational age as the primary predictor of TF (34). This is also a reason to delay initiation of TF among neonates with a gestational age of $<31$ weeks. Additionally, a survey done on feeding practice among 98 Spanish neonatal units revealed that the smaller GA was the main predictor for delayed initiation of TF(35). This is also supported with a prospective follow up study conducted in teaching university hospitals in Ethiopia that showed the time neonates kept NPO was increased with lower gestational age (25).

The first minute APGAR-score was another statistically significant predictor. The hazard of starting TF among neonates scored below seven APGAR at the first minute was $40 \%$ less likely as compared to neonates with a seven and above score. This finding might be because that first-minute APGAR-score is the signal of intrauterine hypoxia which is an indication of decreased blood flow to GIT and increased risk of NEC.

Likewise, the hazard among neonates diagnosed with perinatal asphyxia was $37 \%$ less likely to start TF compared with their counterparts. This might be due to professionals' fear of necrotizing enterocolitis and feeding intolerance secondary to intrauterine hypoxia and decreased blood flow to GIT. This finding is supported with an observational study in Spain, reported that perinatal asphyxia was the reason for the delay in $88 \%$ of the neonate (35). But, contrary to this, the Ethiopian national NICU guideline recommended that TF can be started for asphyxiated neonates if the neonate is passing meconium, clear gastric content, normo-active bowel sound (30). Additionally, a guideline on preterm neonates recommended that birth asphyxia was not a contraindication to initiate TF (38).

Another statistically significant predictor was hemodynamic instability. With this regard, the hazard of starting TF among neonates who have hemodynamic instability was $67 \%$ less likely compared to neonates with the absence of these problems. This indicates neonates who had hemodynamic instability were more likely have delayed initiation of TF than those who had no such problems. The presence of these groups of problems such as blood group and RH incompatibility, anemia, polycythemia, and bleeding disorders may affect clinicians' decision to initiate TF due to fear of perceived feeding intolerance and necrotizing enterocolitis. This finding is supported by an observational study in Spain that reported hemodynamic instabilities were the reason for the delay to start TF in $100 \%$ of the neonates 
(35). Another study conducted in regional referral hospitals in Tanzania showed hemodynamic instability and its perceived risk of necrotizing enterocolitis was the reason for the delayed initiation of TF (39).

Furthermore, the hazard of starting TF in neonate with respiratory distress syndrome was $50 \%$ less likely among neonates compared with their counterparts. This may be because the presence of respiratory distress might be aggravated with pressure from the abdominal cavity that is further complicated by physiological instability with bradycardia and desaturation events, which have been associated with an increased risk of aspiration during feeding (41). This may influence professionals' decision to delay starting TF. Contrary to this finding, some guidelines across the globe recommend a minimal EF can be initiated in neonates with respiratory distress syndrome within the first 24 hours of life (38).

Place of delivery was also found to be statistically significant predictors of time to initiate TF. Neonates born out of the study hospitals were $48 \%$ less likely to start TF than those born within the study hospitals. However, there is a lack of evidence to support the relationship between place of birth and time to initiate trophic feeding; the possible explanation might be due to transportation delay.

The hazard of giving delivery with a cesarean section was $37 \%$ less likely to start TF as compared with those delivered via spontaneous vaginal delivery. Mothers who gave birth with cesarean section, might not bring expressed milk upon request by the clinician. In contrast to this finding, research reports revealed that mode of delivery had no statistically significant effect on time to initiate enteral feeding(40). This difference might be due to the difference in sample size which was 729 in the previous study and 210 in this study, difference in the study design, and general socio-demographic characteristics of the study population

\section{Limitation of the study}

The sample size was calculated with Stata package because of an absence of previous related literature that reported essential parameters used for calculation.

\section{Conclusions}

There is a considerable delay to initiate trophic feeding. The time of starting trophic feeding was delayed in the study hospitals. After adjustment for confounding, APGAR-score of less than seven, gestational age of below 34 weeks, being out-born, cesarean delivery, presence of respiratory distress syndrome, perinatal asphyxia, and hemodynamic instability were predictors found to hinder the time of starting trophic feeding.

\section{List Of Abbreviations}




\begin{tabular}{|ll|}
\hline AGA & Appropriate for Gestational Age \\
\hline AHR & Adjusted Hazard Ratio \\
\hline APGAR & Appearance, Pulse, Grammies, Activity, Respiration \\
\hline BW & Birth Weight \\
\hline CHR & Crude Hazard Ratio \\
\hline Cl & Confidence Interval \\
\hline CPAP & Continuous Positive Airway Pressure \\
\hline DMCSH & Debre Markos Comprehensive Specialized Hospital \\
\hline ELBW & Extremely Low Birth Weight \\
\hline EN & Enteral Nutrition \\
\hline EF & Enteral Feeding \\
\hline EFY & Ethiopian Fiscal Year \\
\hline FHCSH & Felege Hiwot Comprehensive Specialized Hospital \\
\hline GA & Gestational Age \\
\hline HR & Hazard Ratio \\
\hline IQR & Interquartile Range \\
\hline IUGR & Intrauterine Growth Restriction \\
\hline KMC & Kangaroo Mother Care \\
\hline LBW & Low Birth Weight \\
\hline LGA & Large For Gestational Age \\
\hline MEN & Minimal Enteral Nutrition \\
\hline NEC & Necrotizing Enterocolitis \\
\hline NICU & Neonatal Intensive Care Unit \\
\hline PPH & Postpartum Hemorrhage \\
\hline SPO & Nothing Per Os \\
\hline SGA & Standard Deviation \\
\hline Small for Gestational Age \\
\hline Tibebe Ghion Comprehensive Specialized Hospital \\
\hline SPCal Package for Social Sciences \\
\hline SPS
\end{tabular}




\section{Declarations}

\section{Ethics approval and consent to participate}

This study was carried out after getting ethical clearance and paper approval from the Ethical Review Committee of Health Science College, Debre Markos University. Permission was obtained from each hospital to collect the data. Additionally, written informed consent was taken from the mother/caregiver of the neonate after explanation of the objectives of the research, benefit, and risk of participation, absence of any special incentives, and any other concerns related to research. To maintain confidentiality, each and every one collected data were coded and locked in a separate room prior to enter into the computer. After entering into the computer all data were protected by password. Names and unique medical registered numbers (MRN) were not incorporated in the data collection set-up.

\section{Consent for publication}

Not applicable

\section{Availability of data and material}

Additional file: Data abstraction tool

Data set: The data sets used and/or analyzed during the current study are available from the corresponding author on reasonable request.

\section{Competing interests}

The authors have declared that they have no competing interest.

\section{Authors' contribution}

DA: the conception of the research idea, methodology, data collection, analysis and interpretation. YT, TE: supervision, methodology, analysis, result interpretation and editing

EA, MA, BE: analysis, result interpretation and manuscript write-up. All authors have read and approved the final manuscript.

\section{Funding}

Not applicable. 


\section{Acknowledgment}

The authors would like to acknowledge the Debre Markos University of Gondar, College of Health Sciences for support of this research project. The authors also extend their special thanks to both data collectors and supervisors.

\section{References}

1. Vogel JP, Chawanpaiboon S, Moller A-B, Watananirun K, Bonet M, Lumbiganon P. The global epidemiology of preterm birth. Best Practice \& Research Clinical Obstetrics \& Gynaecology. 2018;52:3-12.

2. Pinto F, Fernandes E, Virella D, Abrantes A, Neto MT. Born Preterm: A Public Health Issue. Portuguese Journal of Public Health. 2019;37(1):38-49.

3. Richard J. Martin AAF, Michele C. Walsh. NEONATAL-PERINATAL MEDICINE, Diseases of the Fetus and Infant. 10th ed2015.

4. Dutta S, Singh B, Chessell L, Wilson J, Janes M, McDonald K, et al. Guidelines for feeding very low birth weight infants. Nutrients. 2015;7(1):423-42.

5. Kültürsay N, Bilgen $\mathrm{H}$, Türkyılmaz C. Turkish Neonatal Society guideline on enteral feeding of the preterm infant. Turk Pediatri Ars. 2018;53(Suppl 1): S109-S18.

6. A. L. Enteral nutrition. In Nutritional Needs of the Preterm Infant: Scientific Basis and Practical Guidelines, Tsang RC, et al., eds. Philadelphia: Lippincott Williams \& Wilkins,; 1993.

7. CHURCHILL E. feeding and nutrion in preterm infant,. In: Elizabeth A. Jones M, Caroline King, BSc(Hons), SRD, editor. Health, Fitness \& Dieting: Amazon.com; 2005.

8. Cheah F-C. feeding the preterm infant, a practical handbook. 2017.

9. Ramani M, Ambalavanan N. Feeding practices and necrotizing enterocolitis. Clin Perinatol. 2013;40(1):1-10.

10. Christine A. Gleason M, Sandra E. Juul, MD, PhD. Avery's Diseases of the Newborn. 10th ed. Washington2018.

11. KLEINGMAN SG, BLUM, SHAM, TASKER, WILSON. Nelson Textbook of Pediatrics. 21th ed.

12. Klingenberg C, Embleton ND, Jacobs SE, Connell LAF, Kuschel CA. Enteral feeding practices in very preterm infants: an international survey. Archives of Disease in Childhood - Fetal and Neonatal Edition. 2012;97(1):F56.

13. de Waard M, Li Y, Zhu Y, Ayede Al, Berrington J, Bloomfield FH, et al. Time to Full Enteral Feeding for Very Low-Birth-Weight Infants Varies Markedly Among Hospitals Worldwide But May Not Be Associated With Incidence of Necrotizing Enterocolitis: The NEOMUNE-NeoNutriNet Cohort Study. JPEN Journal of parenteral and enteral nutrition. 2019;43(5):658-67.

14. Akram Sallakh-Niknezhad*1 MFB-H, MD; Niloofar Satarzadeh1,MSc; Morteza Ghojazadeh3, PhD, and Golnesa Sahnazarli1, MSc. Early versus Late Trophic Feeding in Very Low Birth Weight Preterm 
Infants. Iran J Pediatr. 2012;زVol 22( No 2).

15. McClure RJ, Newell SJ. Randomised controlled study of clinical outcome following trophic feeding. Archives of Disease in Childhood - Fetal and Neonatal Edition. 2000;82(1):F29.

16. Krishnamurthy S, Gupta P, Debnath S, Gomber S. Slow versus rapid enteral feeding advancement in preterm newborn infants 1000-1499g: a randomized controlled trial. Acta Paediatrica. 2010;99(1):42-6.

17. Liu J, Kong K, Tao Y, Cai W. Optimal timing for introducing enteral nutrition in the neonatal intensive care unit. Asia Pacific journal of clinical nutrition. 2015;24(2):219-26.

18. Hay Jr WW. Strategies for feeding the preterm infant. Neonatology. 2013;94(4):245-54.

19. King C. What's new in enterally feeding the preterm infant? Archives of disease in childhood Fetal and neonatal edition. 2010;95(4):F304-8.

20. Kennedy KA, Tyson JE. Early versus delayed initiation of progressive enteral feedings for parenterally fed low birth weight or preterm infants. Cochrane Database of Systematic Reviews. 2000(1).

21. Ho M-Y, Yen Y-H. Trend of Nutritional Support in Preterm Infants. Pediatrics \& Neonatology. 2016;57(5):365-70.

22. McKenzie BL, Edmonds L, Thomson R, Haszard JJ, Houghton LA. Nutrition Practices and Predictors of Postnatal Growth in Preterm Infants During Hospitalization: A Longitudinal Study. J Pediatr Gastroenterol Nutr. 2018;66(2):312-7.

23. Sallakh-Niknezhad A, Bashar-Hashemi F, Satarzadeh N, Ghojazadeh M, Sahnazarli G. Early versus Late Trophic Feeding in Very Low Birth Weight Preterm Infants. Iranian Journal of Pediatrics. 2012;22(2):171-6.

24. Reeding RA. THE NUTRIENT INTAKES AND FEEDING PRESCRIPTIONS OF LOW BIRTH WEIGHT INFANTS AT CHRIS HANI BARAGWANATH ACADEMIC HOSPITAL: Stellenbosch University; 2017.

25. Gidi NW, Mekasha A, Nigussie AK, Goldenberg RL, McClure EM, Worku B, et al. Preterm Nutrition and Clinical Outcomes. Global pediatric health. 2020;7:2333794X20937851.

26. Edmond KM, Kirkwood BR, Amenga-Etego S, Owusu-Agyei S, Hurt LS. Effect of early infant feeding practices on infection-specific neonatal mortality: an investigation of the causal links with observational data from rural Ghana. The American Journal of Clinical Nutrition. 2007;86(4):112631.

27. Moyses HE, Johnson MJ, Leaf AA, Cornelius VR. Early parenteral nutrition and growth outcomes in preterm infants: a systematic review and meta-analysis. The American Journal of Clinical Nutrition. 2013;97(4):816-26.

28. Nakubulwa C, Musiime V, Namiiro FB, Tumwine JK, Hongella C, Nyonyintono J, et al. Delayed initiation of enteral feeds is associated with postnatal growth failure among preterm infants managed at a rural hospital in Uganda. BMC pediatrics. 2020;20(1):86.

29. PIYA BISWAS1 JS, MUJIBUL HOQUE2, MD. MONIR HOSSAIN3, MANAJJIR ALI4. Comparative Study of Early Versus Delayed Enteral Feeding in Development of Necrotizing Enterocolitis for Preterm 
Small for Date Babies. Bangladesh Journal of Child Health. 2018; Vol 41 No 2(84-91).

30. Federal Ministry of Health E. Neonatal Intensive Care Unit (NICU) Training, Participants' Manual. Addis Ababa2014. p. 194.

31. Berti E, Puglia M, Perugi S, Gagliardi L, Bosi C, Ingargiola A, et al. Feeding Practices in Very Preterm and Very Low Birth Weight Infants in an Area Where a Network of Human Milk Banks Is in Place. Frontiers in Pediatrics. 2018;6.

32. Jackson BN, Kelly BN, McCann CM, Purdy SC. Predictors of the time to attain full oral feeding in late preterm infants. Acta Paediatrica. 2016;105(1):e1-e6.

33. Ogunlesi TA, Ogunfowora OB. The Influence of Method, Timing of Onset and Duration of Enteral Feeding on the Duration of Hospitalization of Newborn Infants in a Nigerian Special Care Baby Unit. Ann Med Health Sci Res. 2015;5(6):397-402.

34. Gregory KE, Connolly TC. Enteral Feeding Practices in the NICU: Results from a 2009 Neonatal Enteral Feeding Survey. Advances in Neonatal Care. 2012;12(1):46-55.

35. Moreno Algarra MC, Fernández Romero V, Sánchez Tamayo T, Espinosa Fernández MG, Salguero García E. Variability in enteral feeding practices of preterm infants among hospitals in the SEN1500 Spanish neonatal network. Anales de Pediatría (English Edition). 2017;87(5):245-52.

36. Ezomike UO, Ugwu EO, Ezomike NE, Eke CB, Ekenze SO. Evaluation of Impact of Perinatal Factors on Time to First Meconium Passage in Nigerian Neonates. Malawi medical journal : the journal of Medical Association of Malawi. 2019;31(2):150-4.

37. Dumpa V, Kamity R, Ferrara L, Akerman M, Hanna N. The effects of oral feeding while on nasal continuous positive airway pressure (NCPAP) in preterm infants. J Perinatol. 2020;40(6):909-15.

38. Smith JR. Early Enteral Feeding for the Very Low Birth Weight Infant: The Development and Impact of a Research-Based Guideline. Neonatal Network. (4):9-19.

39. Hyera RA, Evelyne Kazimoto, Theodore Leyna, Germana McHomvu, Francis Zuechner, Antke. Enhancing early breast milk for sick and preterm neonates admitted at regional referral hospitals in Dar es Salaam, Tanzania. 2020.

40. Kirollos DW, Abdel-Latif ME. Mode of delivery and outcomes of infants with gastroschisis: a metaanalysis of observational studies. Archives of Disease in Childhood - Fetal and Neonatal Edition. 2018;103(4):F355.

41. Pineda R, Prince D, Reynolds J, Grabill M, Smith J. Preterm infant feeding performance at term equivalent age differs from that of full-term infants. Journal of perinatology : official journal of the California Perinatal Association. 2020;40(4):646-54.

42. Bozkurt O, Alyamac Dizdar E, Bidev D, Sari FN, Uras N, Oguz SS. Prolonged minimal enteral nutrition versus early feeding advancements in preterm infants with birth weight $\leq 1250 \mathrm{~g}$ : a prospective randomized trial. The journal of maternal-fetal \& neonatal medicine : the official journal of the European Association of Perinatal Medicine, the Federation of Asia and Oceania Perinatal Societies, the International Society of Perinatal Obstet. 2020:1-7. 
43. Quan MY, Li ZH, Wang DH, Schibler K, Yang L, Liu J, et al. Multi-center Study of Enteral Feeding Practices in Hospitalized Late Preterm Infants in China. Biomedical and environmental sciences : BES. 2018;31(7):489-98.

44. Patwardhan G, Soni A, Rachwani N, Kadam S, Patole S, Pandit A. Factors Associated with Time to Full Feeds in Preterm Very Low Birth Weight Infants. Journal of tropical pediatrics. 2017;64.

45. Ryan TP. Sample size determination and power 2013.

46. Engle WA, American Academy of Pediatrics Committee on F, Newborn. Age terminology during the perinatal period. Pediatrics. 2004;114(5):1362-4.

47. Razak A. Two-Hourly versus Three-Hourly Feeding in Very Low-Birth-Weight Infants: A Systematic Review and Meta-Analysis. Am J Perinatol. 2019.

48. Mercado K, Vittner D, Drabant B, McGrath J. Neonatal Intensive Care Unit-Specific Lactation Support and Mother's Own Breast Milk Availability for Very Low Birth-Weight Infants. Advances in neonatal care : official journal of the National Association of Neonatal Nurses. 2019;19(6):474-81.

Figures

Kaplan-Meier survival estimate of preterm neonates on TF

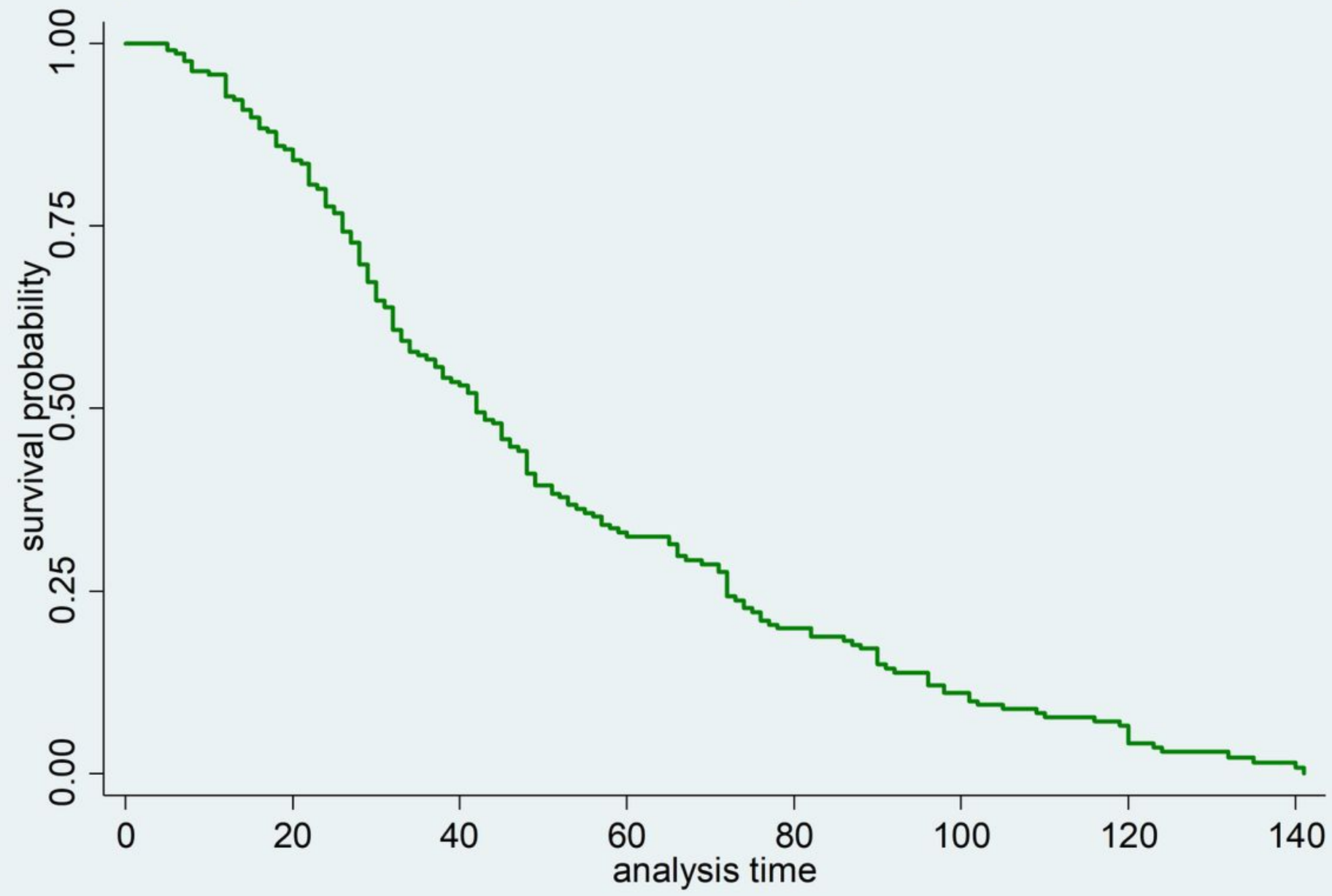


Figure 1

The Kaplan-Meier survival estimates of time to initiate TF among neonates admitted to NICU of DMCSH, FHCSH, and TGCSH, Amhara, Northwest Ethiopia from October to November /2020 ( $n=210)$.

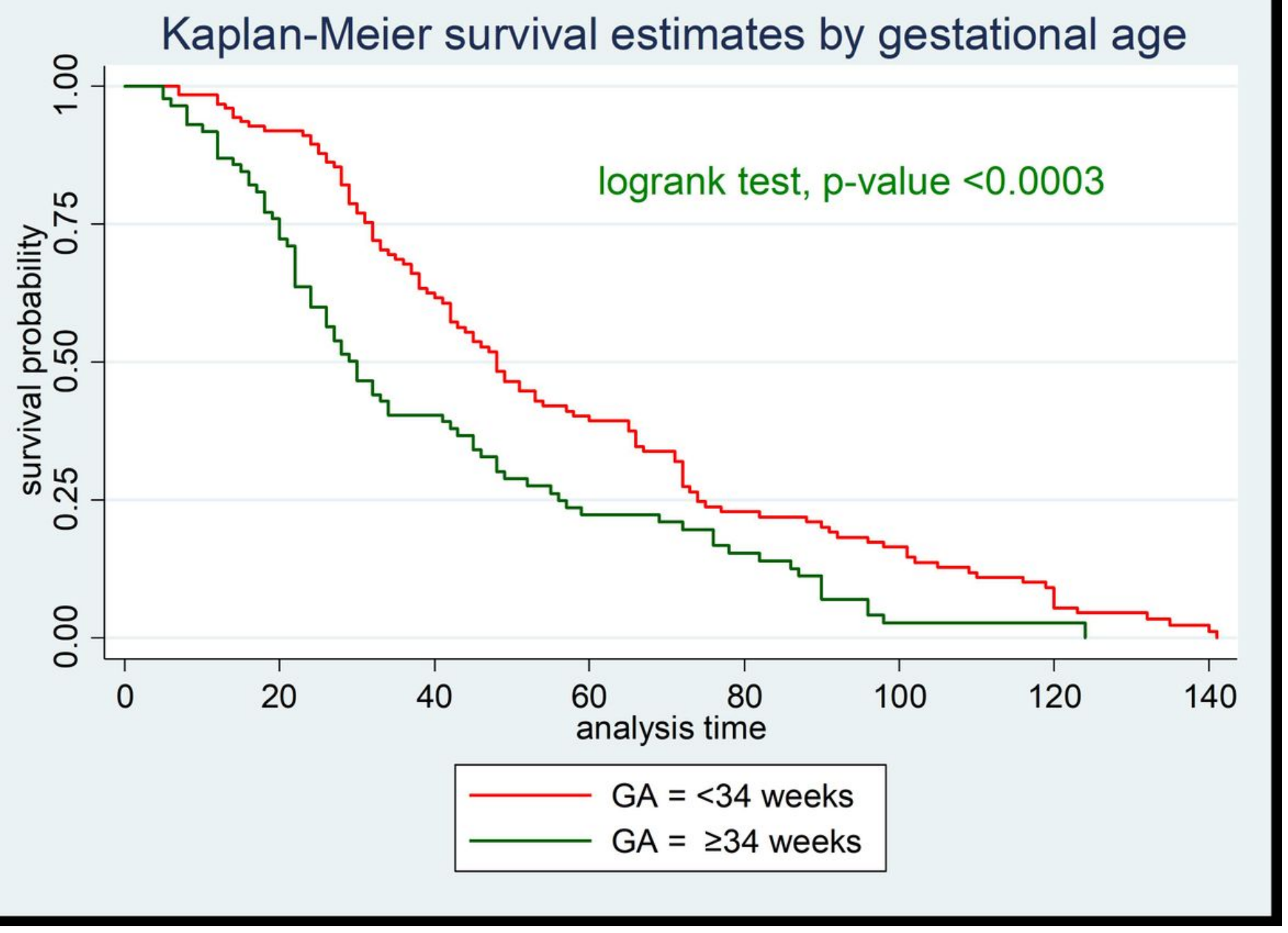

Figure 2

Kaplan-Meier survival estimate of starting TF based on the gestational age of neonates admitted in NICU of DMCSH, FHCSH, and TGCSH, Amhara, Northwest Ethiopia from October to November /2020 $(n=210)$. 


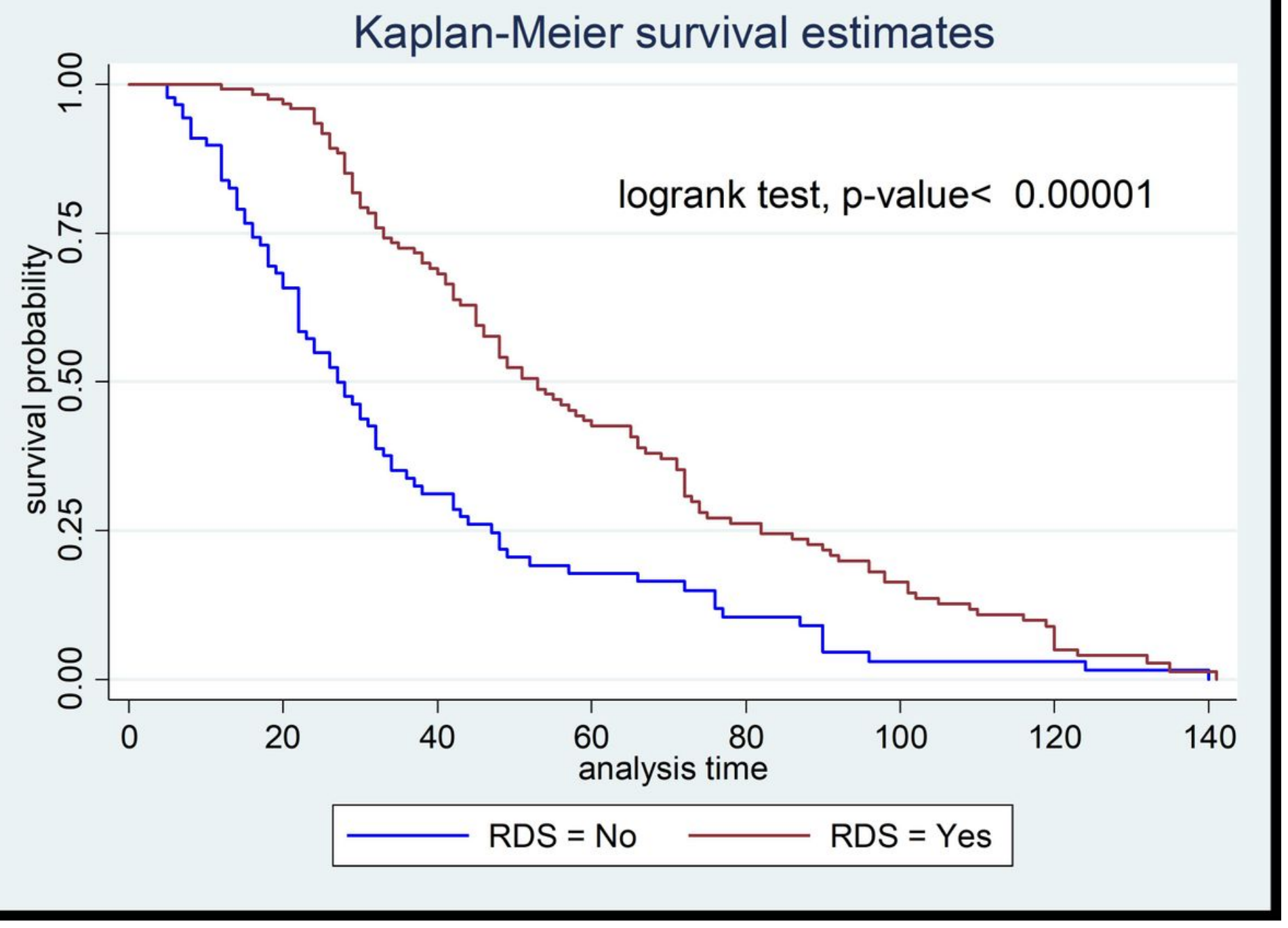

Figure 3

Kaplan-Meier survival estimate of starting TF based on respiratory distress syndrome among neonates admitted in NICU of DMCSH, FHCSH, and TGCSH, Amhara, Northwest Ethiopia from October to November $/ 2020(n=210)$ 


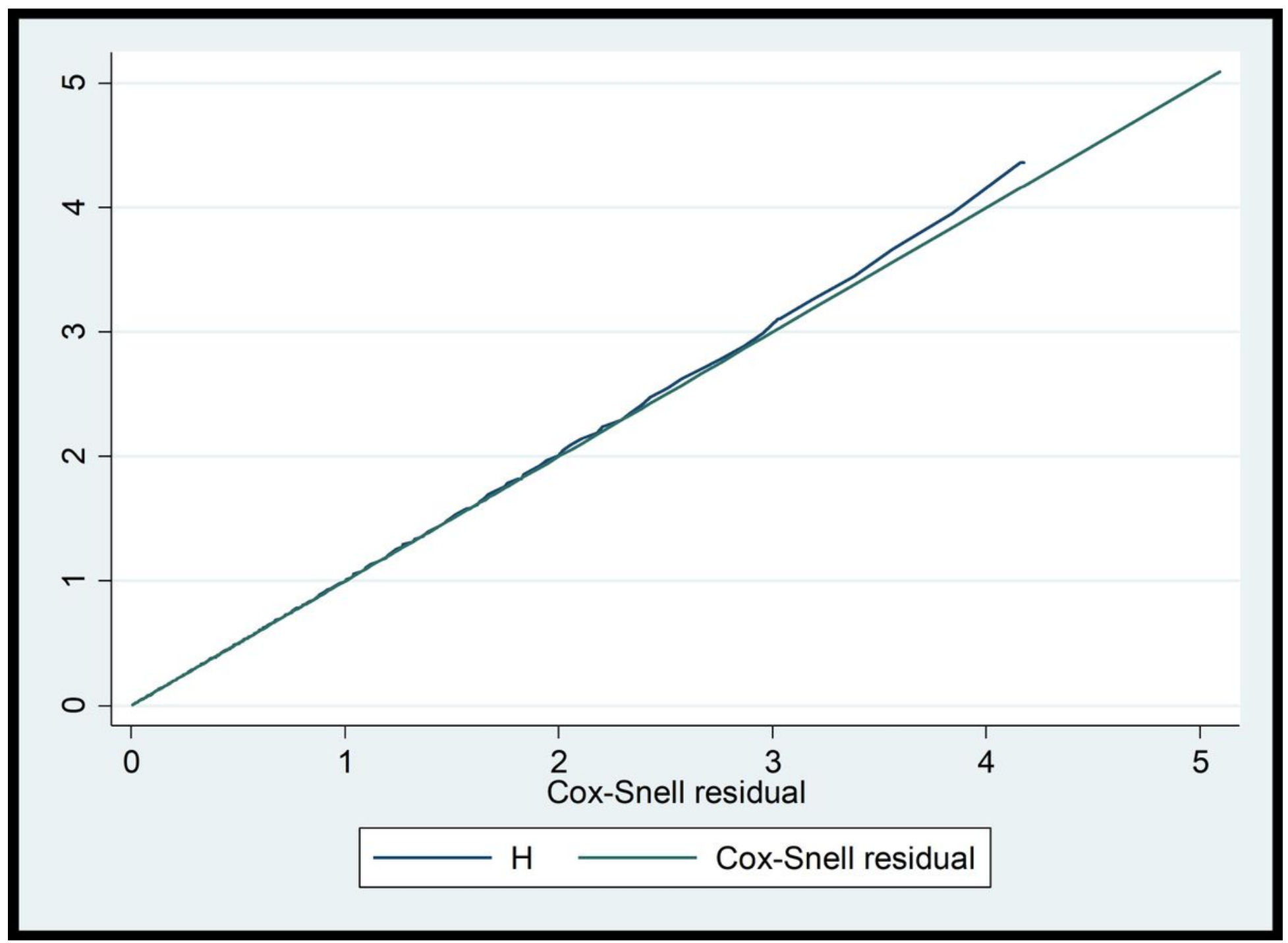

Figure 4

Cox-Snell residual graph, based on the Kaplan-Meier estimated survivor function, to test the overall adequacy of the Cox proportional hazard model of time to initiate TF and its predictors among neonates admitted to NICU of DMCSH, FHCSH, and TGCSH, Amhara, Northwest Ethiopia, 2020 ( $\mathrm{N}=210)$ 


\section{log-log plot by first minute APGAR}

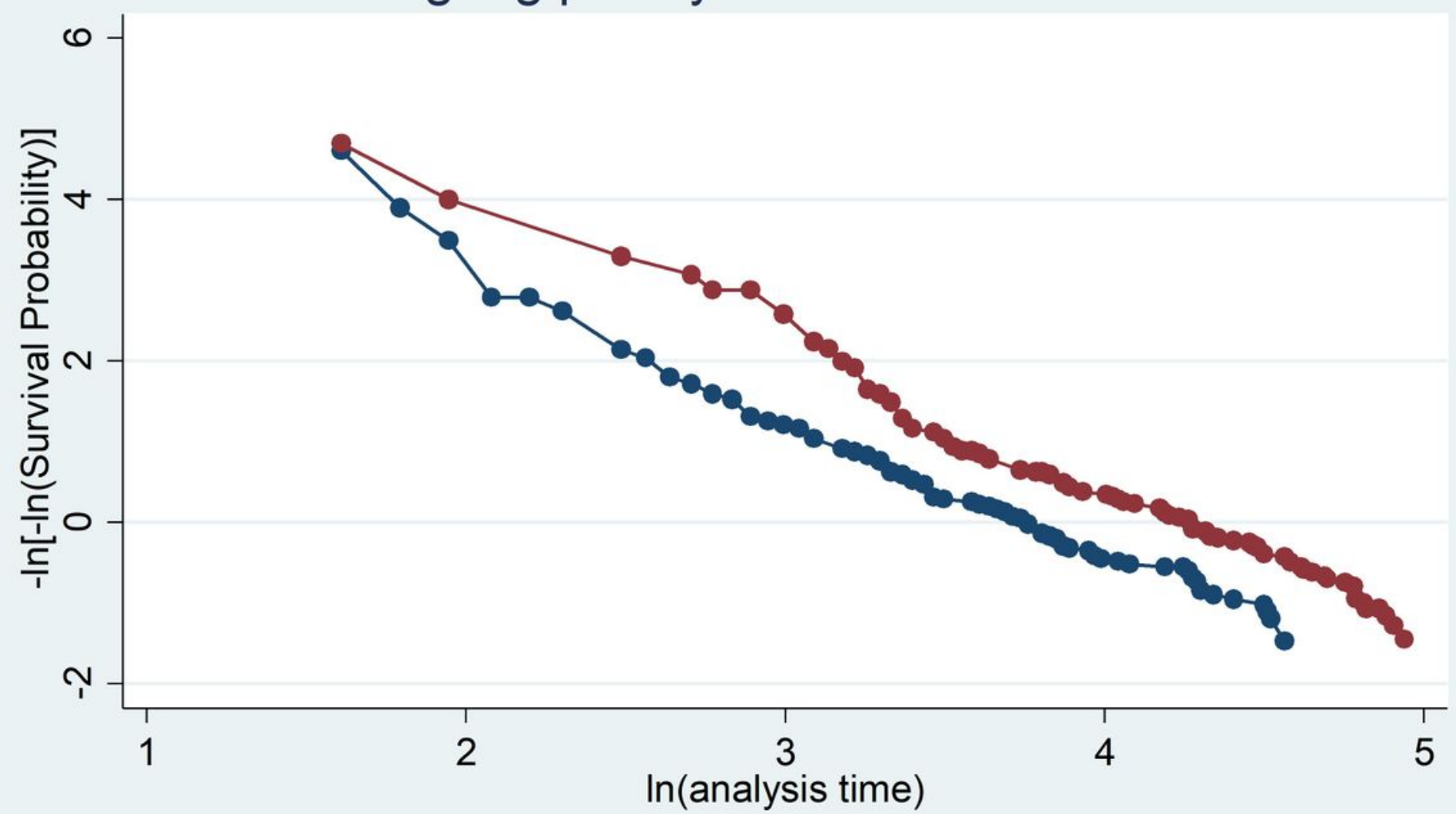

\section{Figure 5}

The Kaplan-Meier survival estimates for APGAR score, at the first minute, of the neonates who were admitted to NICU of DMCSH, FHCSH, and TGCSH, Amhara, Northwest Ethiopia from October to November /2020 ( $\mathrm{n}=210)$ 